\title{
Isolated angioedema: An overview of clinical features and etiology (Review)
}

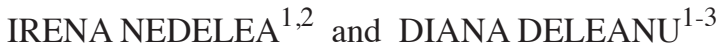 \\ ${ }^{1}$ Allergology and Immunology Discipline, 'Iuliu Hațieganu' University of Medicine and Pharmacy, Cluj-Napoca 400012; \\ Departments of ${ }^{2}$ Allergy and ${ }^{3}$ Internal Medicine, 'Professor Doctor Octavian Fodor' Regional Institute of \\ Gastroenterology and Hepatology, Cluj-Napoca 400162, Romania
}

Received August 17, 2018; Accepted October 3, 2018

DOI: $10.3892 /$ etm.2018.6982

\begin{abstract}
Angioedema can occur in isolation, accompanied by urticaria, or as a feature of anaphylaxis in mast cell-mediated disorders, bradykinin-mediated disorders, as well as in others with unknown mechanisms, such as infections, rare disorders, or idiopathic angioedema. In mast cell-mediated angioedema, other signs and symptoms of mast cell-mediator release are frequently seen. However, clear evidence of mast cell degranulation may be absent in histaminergic angioedema. Bradykinin-induced angioedema is not associated with urticaria or other symptoms of type I hypersensitivity reactions. For many of the known triggers of angioedema, the mechanism is unclear. While mast cell and bradykinin-mediated angioedema are relatively well defined in terms of diagnostic and therapeutic approach, angioedema with unknown mechanisms represents a challenge for patients and clinicians alike. Elucidating the clinical pattern and the possible causes of isolated angioedema is the key to a correct diagnosis. This review summarizes the causes, and clinical features of angioedema, with a focus on isolated angioedema.
\end{abstract}

\section{Contents}

1. Introduction

2. Clinical forms of angioedema

3. Conditions that mimic angioedema

4. Conclusions

Correspondence to: Dr Irena Nedelea, Allergology and Immunology Discipline, 'Iuliu Hațieganu' University of Medicine and Pharmacy, 8 Victor Babes Street, 400012 Cluj-Napoca, Romania E-mail: irennedelea@gmail.com

Key words: hereditary angioedema, acquired angioedema, histaminergic angioedema, bradykinin-mediated angioedema, idiopathic angioedema

\section{Introduction}

From a historical perspective, Quincke, a German internist and surgeon first described angioedema, in 1882 (1). Six years later, Osler recognised the hereditary nature of the disease (2). Angioedema manifests as localized, asymmetric, typically nonpruritic cutaneous and/or mucosal swelling, predominantly affecting areas with loose connective tissue. Certain clinical features differentiate angioedema from other types of edema (Table I) $(3,4)$. Angioedema can occur in isolation, accompanied by urticaria, or as a feature of anaphylaxis in mast cell-mediated disorders, bradykinin-mediated disorders, as well as in other conditions with unknown mechanisms, such as infections, rare disorders, or idiopathic angioedema. In mast cell-mediated angioedema, other signs and symptoms of mast cell-mediator release (flushing, urticaria, pruritus, and other end-organ manifestations, such as rhinorrhea, nasal obstruction, bronchospasm, wheezing, dysphonia, stridor, dysphagia, diarrhea, abdominal pains, nausea, vomiting and cardiovascular symptoms) are frequently seen. In contrast, bradykinin-induced angioedema is not associated with urticaria or other symptoms of type I hypersensitivity reactions. Clinical response to antihistamines is a cardinal feature of mast cell-mediated angioedema, also known as histaminergic angioedema, while bradykinin-mediated angioedema is nonhistaminergic, or refractory to antihistamine therapy (3).

In this review, the possible causes and the clinical picture of angioedema, with a focus on isolated angioedema are discussed.

\section{Clinical forms of angioedema}

Two main clinical forms of angioedema have been described: mast cell-mediated angioedema and bradykinin-mediated angioedema (Table II) $(3,5)$.

Mast cell-mediated angioedema generally is accompanied by signs and symptoms of mast cell-mediator release, such as urticaria and not only; it onsets within minutes to hours after allergen exposure, resolves in 24-48 h, and usually responds to antihistamine treatment (4).

Bradykinin-mediated angioedema encompasses a spectrum of rare disorders in which the angioedema is isolated, thus not associated with urticaria, or with other signs of 
Table I. Clinical characteristics of angioedema versus other forms of edema.

Angioedema

Other types of edema

Self-limited, with asymmetric distribution

Onsets in $\mathrm{min} / \mathrm{h}$

Spontaneous resolution in hours/several days

Non-gravitational, non-position dependent

Involves areas with loose connective tissue (lips, eyelids, mouth, throat, uvula, larynx, extremities, genitalia, bowel wall)

Associated with other signs of allergy or anaphylaxis ${ }^{\mathrm{a}}$
Chronic, persistent, symmetric

Tendency to involve gravitational dependent areas; symptoms and signs are related to position

Affects other areas, depending on the underlying condition

Lack of signs of allergy/anaphylaxis

${ }^{a}$ In cases of histaminergic angioedema.

allergic reactions. It usually builds within hours or days, the relationship between the trigger and the inaugural symptoms is not apparent, and it resolves within two to four days. In addition, it does not respond to antihistamine therapy, regardless of dose. In addition, it does not respond to corticosteroids, while epinephrine brings a mild and transient clinical benefit.

Hereditary angioedema (HAE) or inherited C1 inhibitor (C1INH) deficiency is a rare genetic disease caused by deficiency (type I) or dysfunction (type II) of C1INH. Mutations of the C1INH gene, SERPING1, are the main abnormality in both HAE subtypes $(6,7)$.

HAE due to C1INH deficiency is an autosomal dominant disorder with an almost complete penetrance affecting $50 \%$ of male and female children of parents with HAE. The overall prevalence ranges from $1: 30,000$ to $1: 80,000$ in the general population. Type I HAE accounts for approximately $85 \%$ of cases, with type II HAE affecting the other $15 \%$ (8).

In addition, a type III form of HAE, with C1INH normal function and expression has been described. No mutations of the SERPING gene were identified in affected individuals. Type III HAE also shows an autosomal dominant pattern of inheritance. It predominantly affects female population and it tends to be less severe in the minority of men suffering from the disease. Mutations in the factor XII gene were identified in some of the cases. In addition, estrogens exacerbate the disease in many of the affected individuals (9).

All clinical forms of HAE are characterized by recurrent attacks of isolated nonpruritic, nonpitting angioedema, affecting the extremities, genitourinary, upper respiratory and gastrointestinal tracts (10). There is a wide variability in the kinetics of angioedema episodes. Usually, angioedema develops gradually, builds in the first $24 \mathrm{~h}$, is self-limited, but temporarily debilitating, usually resolving over the next 48-72 h. However, some attacks progress rapidly, within minutes, while others last for more than 5 days. Fatalities from laryngeal attacks have been reported. Angioedema episodes most commonly involve the extremities and the gastrointestinal tract, with each accounting for approximately $50 \%$ of all attacks. More than half of the patients will experience at least one laryngeal attack (11). Infrequently, angioedema has a different distribution, involving the brain, heart, kidney, or joints. Prodromal symptoms, such as erythema marginatum, a sense of skin tightening or localized tingling, as well as nonspecific manifestations (fatigue, malaise, flulike symptoms, thirst, nausea, and mood changes) precede the attacks by $24-48 \mathrm{~h}$ in up to $50 \%$ of patients $(8,10)$. Concerning the onset of the disease, the clinical picture becomes clinically apparent before the first ten years of life in almost $50 \%$ of cases, with some cases manifesting the disease by the first year of age. The disease tends to worsen during puberty and to improve with aging. However, some patients continue to experience attacks throughout their life. Rare cases of HAE patients who do not exhibit the disease were identified. HAE exacerbations are episodic, with some patients experiencing symptoms as frequent as twice a week. The pattern of disease severity is variable and individual $(8,10,12,13)$. The disease significantly impairs the quality of life. Genitourinary attacks may lead to temporary anuria, while gastrointestinal tract attacks can result in severe symptoms and the formation of 'third spacing' of fluid can induce hypotension (8).

Several precipitating factors have been identified: mild trauma and iatrogenic trauma, such as dental surgery, intubation, or other medical procedures, emotional stress, pregnancy, and estrogen therapy. In addition, ACEI therapy has the potential to unmask an underlying HAE. Trauma and emotional stress proved to be the most frequent triggers of symptoms. The level of trauma required to induce symptoms varies greatly from one patient to another. In some cases, mild trauma, such as clapping of hands or prolonged sitting may cause an attack $(8,14)$.

Acquired C1INH deficiency is sporadic and relatively rare, accounting for 1:100,000 to 1:500,000. Both sexes are equally affected and it preponderantly occurs in the elderly, particularly in those with autoimmune or lymphoproliferative disorders. The proposed mechanism is the presence of autoantibodies against C1INH. A 2016 study reported that 33\% of patients presenting with acquired angioedema had or would develop non-Hodgkin lymphoma. The enrolled patients (62.5\%) were diagnosed with non-Hodgkin lymphoma at the onset of angioedema or up to 7 years later (15). Acquired angioedema has been associated with several other disorders (Table III).

Angiotensin convertase inhibitor induced angioedema represents up to $40 \%$ of angioedema cases referred to the Department of Emergency (36). Angioedema occurs in $0.1-0.7 \%$ of patients treated with ACEI. Of these, $25-39 \%$ 
Table II. Types of angioedema.

\begin{tabular}{|c|c|c|c|}
\hline Type & Pathophysiology & Affected population & Prevalence \\
\hline \multicolumn{4}{|c|}{ Bradykinin-mediated angioedema (non-histaminergic) } \\
\hline Type I HAE & $\begin{array}{l}\text { C1INH deficiency, caused by } \\
\text { mutation in SERPING1 gene }\end{array}$ & All & $\sim 1: 50,000$ \\
\hline Type II HAE & $\begin{array}{l}\text { Functional C1INH } \\
\text { deficiency, caused by } \\
\text { SERPING2 gene mutation }\end{array}$ & All & $\sim 1: 250,000$ \\
\hline $\begin{array}{l}\text { Type III HAE } \\
\text { with normal C1INH } \\
\text { (both antigen and function) }\end{array}$ & $\begin{array}{l}\text { Unknown, some of the } \\
\text { patients exhibit defects in } \\
\text { factor XII gene }\end{array}$ & Predominantly women & Unknown \\
\hline Acquired C1INH deficiency & $\begin{array}{l}\text { Deficiency of C1INH by } \\
\text { consumption, or blocking } \\
\text { by autoantibodies } \\
\text { against C1INH }\end{array}$ & $\begin{array}{l}\text { Older patients, frequently } \\
\text { linked to underlying } \\
\text { disease (autoimmune, } \\
\text { lymphoproliferative disorder) }\end{array}$ & $\sim 1: 250,000$ \\
\hline ACEI-induced angioedema & $\begin{array}{l}\text { Inhibition of bradykinin } \\
\text { catabolism }\end{array}$ & $\begin{array}{l}\text { All, with an increased prevalence } \\
\text { in African-Americans }\end{array}$ & $\sim 1: 250$ \\
\hline Non-histaminergic idiopathic & Unknown & Unknown & Unknown \\
\hline \multicolumn{4}{|c|}{ Mast cell-mediated angioedema (histaminergic) } \\
\hline $\begin{array}{l}\text { Angioedema accompanied } \\
\text { by acute urticaria }\end{array}$ & Release of histamine & All & $\sim 20 \%$ of population \\
\hline $\begin{array}{l}\text { Angioedema in the context } \\
\text { of anaphylaxis }\end{array}$ & Release of histamine & All & $0.3-5.1 \%$ of population \\
\hline $\begin{array}{l}\text { Angioedema accompanied } \\
\text { by CU }\end{array}$ & Release of histamine & $\begin{array}{l}\text { All, more common in } \\
\text { adults, women affected } \\
\text { twice as often as men }\end{array}$ & $\begin{array}{l}\text { CU affects } \sim 1 \% \\
\text { of population } \\
40 \% \text { of cases associate } \\
\text { angioedema. Angioedema } \\
\text { is the main manifestation } \\
\text { in } 10 \% \text { of CU cases }\end{array}$ \\
\hline
\end{tabular}

HAE, hereditary angioedema; C1INH, C1 esterase inhibitor; SERPING, serpin family G member; ACEI, angiotensin-converting-enzyme inhibitor; $\mathrm{CU}$, chronic urticaria.

affects the upper respiratory tract, being potentially lethal. Most often, angioedema is located at the cephalic extremity, manifesting as palpebral, lingual or lips edema, or even laryngeal edema, which, in severe forms, can lead to death by asphyxia, but can also affect the digestive tract: abdominal pain syndrome, nausea, vomiting, with sudden onset. Sartans may induce similar ACEI manifestations. Patients with ACEI-induced angioedema (1.5-10\%) develop angioedema to sartans. Administration of ACEI or sartans may unmask an underlying hereditary angioedema. In this context, it is recommended to rule out $\mathrm{HAE}$ in cases of $\mathrm{ACEI} / \mathrm{sartan}-$ induced angioedema (3). Approximately $50 \%$ of cases occur as early as in the first week of treatment $(16,17)$. Sometimes, angioedema or digestive manifestations may occur years after initiation of ACEI/sartan therapy (8). Angioedema is intermittent despite the daily therapy, which may cause confusion and misdiagnosis. Moreover, attacks can reoccur weeks or months after treatment discontinuation (18). Overproduction and/ or reduction of bradykinin degradation induces vasodilation and increased vascular permeability, clinically expressed by isolated angioedema and is the mechanism of production of this disease. Mast cells do not degranulate, which is why pruritus and urticaria are absent. The mechanism by which sartans induce angioedema is insufficiently elucidated $(3,8)$.

\section{Conditions that mimic angioedema}

Several disorders may be mistaken for angioedema. Cutaneous edema is found in contact dermatitis, cellulitis, erysipelas, rosacea, autoimmune disorders, superior vena cava syndrome, parasitic infections, hypothyroidism or cheilitis granulomatosa.

Contact dermatitis can cause dramatic facial and/or eyelid swelling in response to topical agents (cosmetics or pharmaceutical). Clinical signs, such as erythema, pruritus, or burning of the skin are indicative of contact dermatitis and help rule out the diagnosis of angioedema. In addition, resolution of contact dermatitis may cause peeling, which is absent in angioedema (37).

In contrast to angioedema, cellulitis and erysipelas are accompanied by erythema, pain, and may be associated with fever. Rosacea may be associated with facial lymphedema. However, flushing and warmth of the face, which are typical features of rosacea, are absent in angioedema. 
Table III. Conditions associated with angioedema.

\begin{tabular}{lc}
\hline Conditions & Refs. \\
\hline Hypereosinophilic syndrome & $(19)$ \\
Gleich syndrome & $(20)$ \\
T-cells lymphoma & $(21)$ \\
Multiple myeloma & $(22)$ \\
Chronic lymphocytic leukemia & $(23)$ \\
Myelofibrosis & $(24)$ \\
Waldenström macroglobulinemia & $(25)$ \\
Non-Hodgkin lymphoma & $(15)$ \\
Essential cryoglobulinemia & $(26)$ \\
Cold urticaria & $(27)$ \\
Urticaria vasculitis & $(28)$ \\
Livedo reticularis & $(29)$ \\
Lupus, scleroderma & $(30,31)$ \\
Rectal carcinoma & $(32)$ \\
MGUS & $(33)$ \\
Infection with Helicobacter pylori or & $(34,35)$ \\
Echinococcus granulosis &
\end{tabular}

MGUS, monoclonal gammopathy of uncertain significance.

Blepharochalasis syndrome, characterized by recurrent episodes of upper eyelid unilateral or bilateral edema, leading to atrophy and discoloration of the affected skin may be mistaken for angioedema (38). Facial edema can be seen in patients with autoimmune disorders, such as lupus and in early stages of scleroderma (31). Hypothyroidism causes, in severe forms, myxedema, persistent generalized edema or edema of the face. Parasitic infestations with American trypanosomiasis (Chagas disease) can cause significant palpebral and periorbital edema, also known as Romana's sign (39).

Superior cava syndrome, and head and neck, lymphoma, or pulmonary tumors can induce persistent, progressive, localized edema (40). Melkersson-Rosenthal syndrome or Miescher's cheilitis (cheilitis granulomatosa) is a rare disease, consisting of initially recurrent and eventually permanent facial and lip angioedema, which may be mistaken for angioedema. Geographic tongue and neurological findings in these patients help to confirm the diagnosis (41). Generalized recurrent edema can also occur in some female patients during their menstruation. Sometimes, it is impossible to place angioedema in a clinical context. In clinical practice, idiopathic nonhistaminergic angioedema cases are increasingly seen.

\section{Conclusions}

Angioedema typically manifests as bouts of swelling involving cutaneous or mucosal surfaces. Most often, angioedema is mast cell mediated, being included within the spectrum of urticarial disorders. However, non-mast cell-mediated forms of angioedema can pose difficult challenges to clinicians. Isolated non-histaminergic angioedema is found in types I-III hereditary angioedema, in several acquired forms of angioedema, associated to ACEI/sartan therapy, or with a myriad of hema- tological, autoimmune, or neoplastic disorders. ACEI/sartan induced angioedema may unmask an underlying hereditary angioedema. Elucidating the clinical features and the possible causes of isolated angioedema is the key to a correct diagnosis.

\section{Acknowledgements}

Not applicable.

\section{Funding}

No funding was received.

\section{Availability of data and materials}

Not applicable.

\section{Authors' contributions}

IN and DD were responsible for analysis of data and contributed to writing the manuscript and revising it critically for important intellectual content. Both authors read and approved the final version of manuscript.

\section{Ethics approval and consent to participate}

Not applicable.

\section{Patient consent for publication}

Not applicable.

\section{Competing interests}

The authors declare that they have no competing interests.

\section{References}

1. Quincke H: Acute localized edema of the skin. Monatschr Prakt Dermatol 1: 129-131, 1882.

2. Osler W: Landmark publication from The American Journal of the Medical Sciences: Hereditary angio-neurotic oedema. 1888. Am J Med Sci 339: 175-178, 2010.

3. Craig TJ, Bernstein JA, Farkas H, Bouillet L and Boccon-Gibod I: Diagnosis and treatment of bradykinin-mediated angioedema: Outcomes from an angioedema expert consensus meeting. Int Arch Allergy Immunol 165: 119-127, 2014.

4. Boccon-Gibod I and Bouillet L: Angioedema and urticaria. Ann Dermatol Venereol 141 (Suppl 3): S586-S595, 2014 (In French).

5. Lenschow M, Bas M, Johnson F, Wirth M and Strassen U: A score for the differential diagnosis of bradykinin- and histamine-induced head and neck swellings. Eur Arch Otorhinolaryngol 275: 1767-1773, 2018.

6. Rosen FS, Pensky J, Donaldson V and Charache P: Hereditary angioneurotic edema: Two genetic variants. Science 148: 957-958, 1965.

7. Davis AE III: $\mathrm{C} 1$ inhibitor and hereditary angioneurotic edema. Annu Rev Immunol 6: 595-628, 1988.

8. Zuraw B and Christiansen S: Hereditary angioedema and bradykinin-mediated angioedema. In: Middeleton's Allergy Principles and Practice. Vol 1.8th edition. Elsevier, Philadelphia, PA, pp588-601, 2014.

9. Bork K, Barnstedt SE, Koch P and Traupe H: Hereditary angioedema with normal C1-inhibitor activity in women. Lancet 356: 213-217, 2000.

10. Frank MM, Gelfand JA and Atkinson JP: Hereditary angioedema: The clinical syndrome and its management. Ann Intern Med 84: 580-593, 1976. 
11. Bork K, Meng G, Staubach P and Hardt J: Hereditary angioedema: New findings concerning symptoms, affected organs, and course. Am J Med 119: 267-274, 2006.

12. Agostoni A and Cicardi M: Hereditary and acquired C1-inhibitor deficiency: Biological and clinical characteristics in 235 patients. Medicine (Baltimore) 71: 206-215, 1992.

13. Molina C, Brun J, Coulet M, Betail G, Wahl D and Hartmann L: Diagnostic and therapeutic problems associated with hereditary deficiency of the $\mathrm{C} 1$ esterase inhibitor. Clin Allergy 7: 127-135, 1977.

14. Caballero T, Maurer M, Longhurst HJ, Aberer W, Bouillet L and Fabien V; IOS Study Group: Triggers and prodromal symptoms of angioedema attacks in patients with hereditary angioedema. J Investig Allergol Clin Immunol 26: 383-386, 2016.

15. Castelli R, Wu MA, Arquati M, Zanichelli A, Suffritti C, Rossi D and Cicardi M: High prevalence of splenic marginal zone lymphoma among patients with acquired $\mathrm{C} 1$ inhibitor deficiency. Br J Haematol 172: 902-908, 2016.

16. Slater EE, Merrill DD, Guess HA, Roylance PJ, Cooper WD, Inman WH and Ewan PW: Clinical profile of angioedema associated with angiotensin converting-enzyme inhibition. JAMA 260: 967-970, 1988 .

17. Sabroe RA and Black AK: Angiotensin-converting enzyme (ACE) inhibitors and angio-oedema. Br J Dermatol 136: 153-158, 1997.

18. Campo P, Fernandez TD, Canto G and Mayorga C: Angioedema induced by angiotensin-converting enzyme inhibitors. Curr Opin Allergy Clin Immunol 13: 337-344, 2013.

19. Leiferman KM: Hypereosinophilic syndrome. Semin Dermatol 14: 122-128, 1995.

20. Emonet S, Kaya G and Hauser C: Gleich's syndrome. Ann Dermatol Venereol 127: 616-618, 2000 (In French).

21. Zenone T, Felman P, Malcus C, Durieu I and Durand DV: Indolent course of a patient with hypereosinophilic syndrome associated with clonal T-cell proliferation. Am J Med 107: 509-511, 1999.

22. Geha RS, Quinti I, Austen KF, Cicardi M, Sheffer A and Rosen FS: Acquired C1-inhibitor deficiency associated with antiidiotypic antibody to monoclonal immunoglobulins. N Engl J Med 312: 534-540, 1985.

23. Jung M and Rice L: 'Surgical' abdomen in a patient with chronic lymphocytic leukemia: A case of acquired angioedema. J Gastrointest Surg 15: 2262-2266, 2011.

24. Nilsen A and Matre R: Acquired angioedema and hypocompleentemia in a patient with myelofibrosis. Effect of danazol treatment. Acta Med Scand 207: 123-125, 1980.

25. Khanfar A, Trikha A, Bonds R and Jana B: Angioedema with normal $\mathrm{Clq}$ and $\mathrm{C} 1$ inhibitor: An atypical presentation of Waldenström macroglobulinemia. Int J Hematol 97: 654-656, 2013.
26. Casali P, Borzini P, Pioltelli P, Invernizzi $\mathrm{F}$ and Zanussi $\mathrm{C}$ : Acquired C1-inhibitor deficiency in essential cryoglobulinemia and macrocryoglobulinemia. Acta Haematol 59: 277-284, 1978.

27. Hochstadter EF and Ben-Shoshan M: Cold-induced urticaria: Challenges in diagnosis and management. BMJ Case Rep 2013: bcr2013010441,2013. doi: 10.1136/bcr-2013-010441.

28. Jones JM, Reich KA and Raval DG: Angioedema in a 47-year-old woman with hypocomplementemic urticarial vasculitis syndrome. J Am Osteopath Assoc 112: 90-92, 2012.

29. Maejima $H$ and Katsuoka K: A case of nonepisodic angioedema with eosinophilia associated with livedo reticularis and erythema before onset of edema of the legs. Cutis 93: 33-37, 2014.

30. Habibagahi Z, Ruzbeh J, Yarmohammadi V, Kamali M and Rastegar MH: Refractory angioedema in a patient with systemic lupus erythematosus. Iran J Med Sci 40: 372-375, 2015.

31. Bertinotti L, Miniati I and Cerinic MM: Angioedema and systemic sclerosis. A review of the literature. Scand J Rheumatol 31: 178-180, 2002.

32. Cohen SH, Koethe SM, Kozin F, Rodey G, Arkins JA and Fink JN: Acquired angioedema associated with rectal carcinoma and its response to danazol therapy. Acquired angioedema treated with danazol. J Allergy Clin Immunol 62: 217-221, 1978.

33. Wu MA and Castelli R: The Janus faces of acquired angioedema: C1-inhibitor deficiency, lymphoproliferation and autoimmunity. Clin Chem Lab Med 54: 207-214, 2016.

34. Varvarovska J, Sykora J, Stozicky F and Chytra I: Acquired angioedema and Helicobacter pylori infection in a child. Eur J Pediatr 162: 707-709, 2003

35. Cicardi M,Frangi D, Bergamaschini L, Gardinali M, Sacchi G and Agostoni A: Acquired C1 inhibitor deficiency with angioedema symptoms in a patient infected with Echinococcus granulosus. Complement 2: 133-139, 1985.

36. Gabb GM, Ryan P, Wing LM, Hutchinson KA: Epidemiological study of angioedema and ACE inhibitors. Aust N Z J Med 26: 777-782, 1996.

37. Constantin MM: Value and impact of patch testing in patients with allergic contact dermatitis. Rom J Lab Med 20: 287-292, 2012.

38. Koley S, Mandal RK, Das G, Roy AC and Banerjee S: Unilateral blepharochalasis of right eye. Indian J Dermatol 59: 525-526, 2014.

39. Roveda JM: Romaña's sign. Cole's unilateral trypanosomiasic ophthalmia. Arch Oftalmol B Aires 42: 1-4, 1967 (In Spanish).

40. Herrmann A and Stange T: Facial swelling caused by small cell lung cancer: A rare differential diagnosis of angioedema. HNO 59: 188-191, 2011 (In German).

41. Kakimoto C, Sparks C and White AA: Melkersson-Rosenthal syndrome: A form of pseudoangioedema. Ann Allergy Asthma Immunol 99: 185-189, 2007. 